\title{
A LINGUÍSTICA E O TEXTO LITERÁRIO: PONDERAÇÕES SOBRE A INVESTIGAÇÃO DO REAL
}

\author{
Thaís de Freitas Mondini Belletti \\ Mestre em Estudos da Linguagem pela Pontifícia Universidade Católica do Rio de \\ Janeiro (PUC- RJ) \\ thaisbelletti@gmail.com
}

\section{RESUMO}

O presente trabalho tem como objetivo fazer uma reflexão acerca de uma visão de linguagem que se pretende objetiva para o estudo do real e do texto literário. Sob a ótica de concepções essencialistas de linguagem, a escrita literária estaria ligada somente ao valor estético que a língua pode oferecer, enquanto a escrita científica seria privilegiada nos estudos sobre o meio social. Essa perspectiva passa a ser questionada a partir de abordagens que se desvinculam da noção platônico-aristotélica, que separa o sujeito do objeto. No contexto pós-moderno, questiona-se essa concepção de linguagem e desconstroem-se certos pressupostos metodológicos nas ciências sociais. Propomos, com esse trabalho, refletir sobre as limitações envolvidas no processo investigativo e apontar que a escrita literária deve ser considerada uma prática válida no campo da investigação qualitativa.

Palavras-chave: linguagem, literatura, ciência, investigação.

\section{ABSTRACT}

This work presents a reflection upon a concept of a language that poses as objective for the studies of the real and of literary texts. According to the essentialist perspectives of language, literary writing is linked exclusively to the aesthetic values that language may offer, while scientific writing is perceived to be the fitting language for the studies of social life. However, this perspective is questioned by different approaches that distance themselves from the Aristotelian and Platonic notions that separate subject from object. In the field of Social Sciences, the post-modern context challenges this concept of language, and certain methodological premises are deconstructed. This work proposes a reflection on the limits related to the investigative process, and suggests that literary writing should be considered as a valid practice in the realm of qualitative research.

Keywords: language, literature, science, research. 


\section{Introdução}

Durante séculos, os estudos sobre linguagem foram marcados por grandes questionamentos acerca da relação entre as palavras e o mundo. Desde o período clássico, reflexões sobre como nos referimos ao mundo, ou ao real, através da linguagem, estiveram presentes nos debates filosóficos do Ocidente. O pensamento filosófico, na Grécia, já nasce de uma recusa a um tipo de discurso - o mítico - presente na tradição grega para explicar as coisas. Há, assim, o estabelecimento das explicações racionais e "verdadeiras" na agenda teórica do pensamento ocidental.

Para examinarmos os paradigmas surgidos do pensamento filosófico ocidental no que tange à compreensão acerca da linguagem, precisamos discorrer sobre como as diferentes filosofias da linguagem respondem à questão da significação.

Certamente, desde a Antiguidade clássica, vários pontos de vista surgiram a partir da filosofia do Ocidente, como aqueles encontrados em Platão, Aristóteles até os mais modernos, como Nietzsche, Wittgenstein, e muitos outros. Dentre essa vasta profusão de perspectivas, podemos destacar tendências maiores já manifestadas no período clássico. Foram os gregos que iniciaram, na Europa, uma especulação ampla em relação à linguagem e às questões levantadas pela investigação linguística.

Podemos identificar que as fases principais dos estudos acerca da linguagem na Grécia ocorrem na época dos filósofos pré-socráticos, sofistas, Sócrates, Platão e Aristóteles. No século $\mathrm{V}$ a. C., o ambiente cultural ateniense atraiu grandes pensadores, que buscavam compreender o homem e o mundo ao seu redor. Nesse contexto, no pensamento dos filósofos pré-socráticos, encontramos observações acerca do conhecimento humano que se dividem em visões universalistas e em visões relativistas. 
Dentre esses filósofos, Heráclito é considerado o principal representante do mobilismo, que enxerga a fluidez das coisas, pois, segundo ele, "panta rei" (tudo passa), nada persiste. Ele exemplifica isso, dizendo que não se pode entrar duas vezes no mesmo rio, pois as águas já terão passado e a pessoa já não será a mesma. Segundo essa visão, podemos entender que não existe um conhecimento alcançável, de forma permanente, dado o caráter fluido das coisas. Tal perspectiva contrasta com a visão de Parmênides, que prevê a existência de uma realidade única, imóvel, eterna. No entendimento do filósofo, o movimento é só aparente e, para além do sensível, há a verdadeira realidade. Assim, na visão de Heráclito, o mundo sensível nos dá a impressão de que as coisas não mudam, mas, na verdade, elas estão em constante transformação; já na visão de Parmênides, as coisas não mudam, mas nosso sistema sensorial nos dá a impressão contrária. Na concepção de Parmênides, é através do uso da razão que podemos chegar à essência da realidade.

Ao longo do século $V$ a. C., a crescente participação popular nos instrumentos de poder e a estruturação da democracia em Atenas possibilitaram o surgimento dos filósofos sofistas, pois era preciso exercer a cidadania por meio do discurso. Os sofistas eram vistos como educadores e preparadores para a vida política. O sofista Protágoras aproxima-se das visões relativistas e mobilistas de Heráclito, e não compreende, assim, o entendimento de uma verdade essencial estável. De acordo com essa perspectiva, não há uma verdade a ser revelada, mas as coisas são como nos parecem ser. A percepção do real passa pelos sistemas sensoriais, que variam de acordo com as circunstâncias em que o homem se encontra. Assim, o conhecimento depende necessariamente do homem para se tornar real, pois "o homem é a medida de todas as coisas, das que são como são e das que não são como não são". Também de acordo com a visão relativista, o sofista Geórgias 
defende a impossibilidade de um conhecimento definitivo. Apresentando forte característica sofista, o filósofo entende que, como não temos acesso à natureza das coisas, já que estas não são estáveis, tudo de que dispomos é o discurso. Ao demonstrarem grande interesse pela oratória e pela retórica, Marcondes (1997) aponta que os sofistas contribuíram de forma significativa para o desenvolvimento dos estudos da linguagem para a tradição grega.

Sócrates, por meio dos escritos de outros, e Platão parecem estar vinculados às perspectivas universalistas de Parmênides. Os filósofos partilhavam da ideia de que existe uma verdade única, comum a todos, que pode ser acessada através do pensamento adequado, ou seja, da razão. Martins (2001) destaca que Sócrates estabelece o que seria a função da linguagem: informar sobre as coisas. Sob essa ótica, a linguagem "deve transcender as nossas opiniões e ela mesma, respondendo não à comunidade, mas à realidade" (MARTINS, 2001, p. 22). De acordo com essa perspectiva, a linguagem só pode ter como vocação representar a dimensão fixa do real, a saber, sua essência. Dessa forma, tais teóricos divergem da visão relativista das coisas, em que a realidade tem um caráter dinâmico e mutável. Se aplicarmos a visão relativista aos estudos linguísticos, podemos entender que o significado não existe a priori, em um mundo de ideias perfeitas, mas ele é construído pelo homem.

Discípulo de Platão, Aristóteles afasta-se da visão naturalista de seu mestre, na qual há a separação do mundo das ideias e do mundo sensível. Em relação ao debate quanto à origem da linguagem, Aristóteles posiciona-se a favor das perspectivas convencionalistas, em que a ligação entre os objetos e as ideias se dá de forma arbitrária. Apesar dessas diferenças, Aristóteles não se opõe ao pensamento de Platão, mas o sofistica. A visão aristotélica traz o sujeito para o centro do pensamento. Para o filósofo, a matéria (objetos 
concretos) e a forma (ideias) são indissociáveis, constituindo uma unidade, fundida em um indivíduo. Segundo essa perspectiva, o indivíduo não só é formado de matéria, mas também de ideias, que se organizam no seu interior.

Entendemos, assim, a razão pela qual Aristóteles priorizou o estudo da Lógica, campo de investigação dedicado ao exame da faculdade mental que faz do homem um animal racional. Martins (2001) salienta que uma das preocupações de Aristóteles era exibir uma perspectiva de linguagem a partir da qual as línguas humanas pudessem ser vistas como uma base estável para a manifestação racional do pensamento e como sistemas de representação suficientemente objetivos para funcionar como meios confiáveis de comunicação.

Aristóteles reconhece que a língua apresenta outras funções além de representar a estrutura do pensamento e do real. Em seus tratados intitulados Retórica e Poética, o filósofo teceu considerações acerca da linguagem no que concerne à persuasão e à beleza. Ou seja, as proposições que podem ser objetivamente verdadeiras e representações do real não seriam encontrados no domínio da poética ou da retórica. Tais domínios teriam papel secundário e periférico, enquanto no núcleo da linguagem estaria o pensamento lógico, objetivo e universal sobre as coisas.

Temos, assim, duas posições opostas que estarão presentes nos debates teóricos do pensamento ocidental. De um lado, sob a perspectiva relativista, a linguagem está ligada a uma prática circunstanciada pela variabilidade de cada cultura, história e contato verbal. As palavras não apresentam qualquer sentido perene e a linguagem, assim, não pode ter por função primária descrever objetivamente qualquer ordem universal externa. Do outro lado, sob a perspectiva essencialista, a linguagem tem por função primária a 
descrição explícita do real; as palavras são instrumentos para se referir às coisas de forma objetiva.

De fato, a visão essencialista do mundo domina a história do pensamento ocidental. Dessa forma, a concepção de linguagem como sistema de representação de significados essenciais fixos torna-se a perspectiva hegemônica. Essa perspectiva foi levada ao extremo com a Revolução Científica no século XVII, que passou a encarar os fenômenos naturais como algo que poderia ser explicado objetivamente, por meio da razão. 0 movimento racionalista, difundido a partir do impacto do pensamento de René Descartes, figura central tanto no âmbito científico quanto no âmbito filosófico no século XVII, vê na razão o ponto de partida do processo do conhecimento. Tal perspectiva interpreta que a razão seria o único elemento comum a todos os homens, sendo imutável no tempo e espaço, portanto, universal.

As concepções relacionadas ao método cartesiano influenciaram as modificações a respeito da noção de ciência, a partir do século XVII. Nesse contexto, as teorias no campo das Ciências Humanas apresentavam a pressuposição essencial de que os relatos científicos poderiam descrever objetivamente e com exatidão o indivíduo e a sociedade.

\section{O texto: literatura versus ciência}

Desde o século XVII, o mundo da escrita é dividido em duas partes separadas: a escrita científica e a escrita literária. A literatura é associada à ficção e à subjetividade e a ciência associa-se à linguagem clara, objetiva, aos fatos como eles são. A ficção seria o falso e a ciência seria a verdade. Denzin e Lincoln (2006, p. 22) indicam que as ciências (positivistas) experimentais são muitas vezes vistas como "as grandes façanhas da 
civilização ocidental, supondo-se, em suas práticas, que a 'verdade' possa transcender a opinião e a tendenciosidade pessoal". Dessa forma, a escrita literária ganha status secundário, ligada somente ao valor estético que a linguagem pode oferecer, enquanto a escrita dita científica é privilegiada nos estudos sociais, pretendendo-se uma linguagem objetiva para relatar a relação do indivíduo e seu meio.

No século XIX, o impacto do valor atribuído à ciência atingiu o mundo literário, fazendo com que alguns escritores buscassem aplicar concepções científicas em suas obras literárias. Nesse contexto, no âmbito da literatura, o Realismo pretendeu-se uma escola que buscava retratar o homem e a sociedade em sua totalidade. Buscava-se, por meio de uma linguagem objetiva, e não mais subjetiva, retratar a realidade tida como perversa. Os autores desejavam mostrar a face nunca antes revelada: a do cotidiano massacrante, da falsidade e do egoísmo humano, da impotência do homem comum diante dos poderosos. Honoré de Balzac, tido como um dos fundadores do Realismo, na França, via a sociedade como um "organismo histórico", habitado por "espécies sociais", e os escritores, segundo Richardson (2000), deveriam investigar as razões e as causas dos efeitos sociais.

No final do século XIX, a perspectiva de uma linguagem objetiva e, portanto, científica para descrever a realidade é posta em xeque nos estudos de Friedrich Nietzsche. Como resposta às concepções essencialistas, o filósofo apresenta uma crítica que dialoga diretamente com a metafísica, questionando as verdades do mundo. Nietzsche vai de encontro às ideias de Platão, no que concerne ao plano do inteligível, e postula que cabe ao indivíduo, inserido em um contexto específico, a delimitação dos conceitos. Este, assim, estabelece os sentidos de acordo com suas relações com o mundo. 
Os significados, dessa forma, emergem da interpretação social pelo indivíduo. Nietzsche desconstrói a ideia de essência natural das coisas e defende a inexistência de sentidos únicos, de verdades eternas. Para o filósofo, os significados não são intrínsecos aos objetos, mas são delimitados pelo homem e por suas convenções sociais. 0 perspectivismo de Nietzsche nega a concepção de uma única resposta, de um conhecimento que pretende ser atrelado à razão, e, portanto, verdadeiro, mas crê na multiplicidade de conhecimentos.

Os estudos de Nietzsche exerceram grande impacto em muitos autores que buscaram abordagens que se desvinculassem da perspectiva platônico-aristotélica, que dominavam (e ainda dominam) o campo da linguagem. A abordagem desconstrutivista, iniciada pelo filósofo Jacques Derrida, no século $X X$, é um exemplo marcante. Tal abordagem problematiza as questões ligadas ao conceito de sentido literal e sentido metafórico, numa perspectiva que se opõe à crença de um "significado transcendental" (ARROJO, 2003). A perspectiva que Derrida chamou de "logocêntrica" pressupõe que é fora do sujeito/leitor que se encontra a origem dos significados. O filósofo busca desconstruir tal inferência, ao propor a inseparabilidade entre sujeito e objeto.

Retomando o insight nietzschiano, que indica que a linguagem já nasce metafórica, as considerações de Derrida apontam para a concepção de que qualquer sentido que receba o nome de literal foi uma metáfora. Em outras palavras, o nosso entendimento sobre as coisas é subjetivo; é impossível o sujeito buscar fora de si um sentido neutro ou objetivo.

Tal concepção nega toda uma tradição que associa o sentido literal a uma estabilidade de significado, inerente à palavra ou ao enunciado, que supostamente preserva a linguagem da interferência de quaisquer interpretações. O chamado sentido 
figurado seria, por sua vez, uma derivação do literal e ali se permitiria a criatividade, a ruptura da norma, o inusitado, e a interferência do contexto e dos sujeitos. Nesse caso, a Literatura estaria associada ao domínio da linguagem figurada e não poderia ser usada para retratar o real, ou seja, não poderia estar vinculada aos pressupostos científicos.

\section{Literatura e o pensar sobre a sociedade}

A complexidade das questões relativas às relações entre literatura e sociedade está intimamente associada aos debates filosóficos acerca da linguagem. Grande parte das teorias linguísticas se privilegia enquanto metalinguagem e cultua um discurso científico, que pressupõe desvendar o grande enigma da linguagem. Já a teoria literária enaltece seu suposto acesso exclusivo aos valores estéticos que a linguagem pode nos oferecer.

Arrojo (2003) busca problematizar o embasamento teórico que propõe a divisão de trabalho dos linguistas e dos teóricos literários, fazendo um exame crítico da concepção de metalinguagem. A autora indica que há muito mais em comum entre essas disciplinas do que admitem seus estudiosos. Reconhece, no entanto, que essa é tarefa nada fácil:

É preciso, porém, admitir que a meta que nos propomos é pouco conveniente e nada fácil pois, por um lado, a noção implícita ou explícita da metalinguagem encontra-se fortemente arraigada em nossos meios e, por outro, alimenta e, em troca, é alimentada por várias das dicotomias de ampla acepção em nossa cultura, entre as quais: gramática $\mathrm{x}$ retórica, ciência $\mathrm{x}$ arte, razão $\mathrm{x}$ emoção, sentido literal $\mathrm{x}$ sentido figurado (ARROJO, 2003, p. 57).

Arrojo (2003) destaca que um dos principais sustentáculos da linguística moderna é encontrado na crença de uma metalinguagem isenta de qualquer interferência, qualquer 
contaminação, oriunda da linguagem corriqueira ou leiga (no caso da linguística, seu próprio objeto de estudo, a linguagem-objeto). A própria teoria literária se valeria de uma metalinguagem, dita como neutra, para descrever e explicar a linguagem que elegeu como objeto de investigação, a saber, a linguagem lúdica, emotiva, não-literal.

Dessa forma, nos dois campos de estudo, a concepção de cientificismo é privilegiada para dar conta de um certo rigor teórico. Segundo essa perspectiva, a linguística e a teoria literária, assim como a filosofia da linguagem, estão embasadas em conceitos logocêntricos, que pressupõem a distinção entre uma linguagem objetiva, "correta", para explicar as coisas no mundo e uma linguagem literária, cujo objetivo é a apreciação do belo.

Se na literatura está presente a linguagem subjetiva, figurada, não-científica, como pode ela representar o real? Se partirmos da visão logocêntrica, que crê na possibilidade de uma linguagem objetiva para descrever o mundo e que embasa grande parte das ciências sociais, certamente a literatura não é meio possível. Se, ao contrário, crermos na impossibilidade de uma distinção clara e demarcável entre sujeito e objeto, entre linguagem poética e linguagem comum, entre linguagem e metalinguagem, poderemos encontrar na literatura um campo rico para pensar o indivíduo e o contexto em que vive.

Dentro da concepção antilogocêntrica, Durão (2015) destaca que autores como Adorno, Bakhtin, Benjamin, Deleuse, Foucault, Lacan, dentre outros, se valeram de obras literárias para lançar teorias acerca de estudos dentro da antropologia, história e sociologia. O autor aponta o potencial epistemológico de obras literárias:

É mesmo possível dizer que cada uma das vertentes atuais da teoria, da hermenêutica ou estética da recepção até os queer studies, passando New Historicism e pós-estruturalismo, projeta um modelo de conhecimento específico a 
ser obtido a partir de textos ficcionais. A semiótica encontra neles construções verbais complexas, que permitem uma investigação aprofundada da natureza do signo; a desconstrução depara-se, através deles, com um fértil espaço para a demonstração do auto-desfazer de si da metafísica ocidental; o feminismo identifica tanto um veículo de cristalização de posições de gênero, quanto sua possível subversão; o pós-colonialismo, a consolidação de uma visão etnocêntrica ou a abertura para vozes oprimidas, e assim por diante (DURÃO, 2015, p. 378).

No livro Falando da Sociedade, Becker (2009) busca fazer uma análise de um contexto social também por meio de uma obra ficcional. No capítulo Jane Austen: o romance como análise social, o autor analisa o romance Orgulho e Preconceito, concluindo que, nessa obra, Austen apresenta uma análise bem construída da complexa teia de relações sociais e "carreiras maritais" da aristocracia rural inglesa no início do século XIX. Becker (2009) reconhece que a escritora inglesa não é simplesmente uma narradora de fatos, mas uma romancista que cria personagens que não são reais. Mas, por meio de observações agudas feitas pela narradora, podemos dizer que o livro traz observações detalhadas dos costumes dos habitantes de uma comunidade semelhante a que existia no interior da Inglaterra no século XIX.

Tais descrições, segundo Becker (2009), podem ser comparadas com descrições antropológicas de costumes de casamento em outros tipos de sociedade. $\mathrm{O}$ autor chega a dizer que Orgulho e Preconceito pode ser considerado "uma etnografia da situação local de acasalamento e casamento, algo como aquela que um antropólogo, um sociólogo ou historiador poderia ter produzido" (BECKER, 2009, p. 299). O romance pode até mesmo nos proporcionar uma observação mais aprofundada do indivíduo. Ao lermos o livro, podemos saber mais detalhes sobre o cotidiano daqueles personagens, de suas relações 
emotivas, de seus padrões de comportamento, ou seja, detalhes sutis da interação diária; detalhes esses que provavelmente não encontraríamos em uma obra não ficcional.

Leitores mais céticos, talvez imbuídos de concepções altamente logocêntricas, poderiam claramente dizer que não há razão alguma para considerarmos uma história como essa para uma análise do social, já que os fatos foram, afinal, inventados. Em contraponto a essa visão, Becker (2009) destaca que a maioria dos leitores do livro pensa que aprendeu sobre as questões relacionadas às relações conjugais daquela comunidade naquela época.

Os leitores podem aprender sobre tais coisas, pois as histórias e os detalhes parecem verossímeis, ou seja, estão de acordo com nossos conhecimentos gerais do mundo. Cândido (2006, p. 30) postula que toda obra de arte só está acabada no momento em que repercute e atua, porque "sociologicamente, a arte é um sistema simbólico de comunicação inter-humana e, como tal, interessa ao sociólogo". Nessa relação dialógica, um autor de obra literária apresenta elementos, fornece informações, permitindo que um leitor atento faça reflexões analíticas sobre a realidade da obra, assim como também sobre a sua própria.

De acordo com essa concepção, Durão (2015, p.379) chama atenção para o fato de que "as obras literárias somente existem quando lidas, quando inseridas em um ato, seja o da leitura, seja o da escrita [...] O romance na estante é uma potencialidade". Becker (2009) destaca que obras literárias com frequência oferecem uma alternativa a um tipo de análise sociológica, encontrada em outros campos de estudo; é uma alternativa que apresenta mais detalhes dos processos envolvidos e mais acesso ao pensamento rotineiro dos indivíduos envolvidos. Para Becker (2009), os romances podem ter, portanto, além de suas qualidades como obras literárias, qualidades como análises sociais. 


\section{0 estilo literário em investigação qualitativa}

Certamente, os debates acerca da relação da linguagem com o mundo que ela pretende descrever não se esgotaram com o passar do tempo. Gergen e Gergen (2006) pontuam, no entanto, que nos últimos 10 anos, no domínio qualitativo, houve grandes avanços em áreas dos estudos da linguagem que desafiam a suposição essencial de que os relatos científicos possam representar objetivamente e com exatidão o mundo como ele é.

No contexto pós-moderno, a relação entre a escrita utilizada nas ciências sociais e a escrita literária torna-se mais complexa. A presunção de que exista uma demarcação sólida entre a verdade e a imaginação passa a ser questionada. A questão central da pósmodernidade encontra-se na descrença de que um determinado método ou teoria, discurso ou gênero, seja o meio correto para se chegar a um conhecimento. A crença de que a ciência é capaz de produzir retratos exatos da realidade, de que pode chegar a uma verdade objetiva se enfraquece, causando o que ficou conhecido como a "crise da validade". Isso não significa, no entanto, que outro método passa a obter um status privilegiado, mas todos os métodos são questionados. A superioridade da ciência sobre a literatura, ou da literatura sobre a ciência, não faz mais sentido.

Muitos podem afirmar que esse novo jeito de olhar para questões epistemológicas não permite que se chegue a entendimento algum sobre qualquer que seja o objeto a ser estudado. Fazendo um contraponto a essa ideia, Richardson (2000) indica que a posição pós-moderna nos permite fazer um recorte específico sobre um objeto sem que tenhamos de reivindicar conhecimento sobre o todo. Em outras palavras, ter um entendimento parcial, local, histórico é ter conhecimento. A ideia aqui é reconhecer as 
limitações envolvidas no processo investigativo. $\mathrm{O}$ autor salienta que os escritores, numa investigação qualitativa, "não devem tentar bancar 'Deus', como se fossem 'narradores oniscientes', alegando um 'conhecimento universal e atemporal'”' (RICHARDSON, 2000, p. 8).

Não é correto afirmar que os métodos investigativos mais convencionais sejam rejeitados e tornam-se falsos, mas estes passam a ser, como já mencionado anteriormente, indagados e questionados. Nesse contexto, outros métodos surgem como tentativas de substituir o tradicional esforço de descobrir e de registrar o mundo. Dentre essas tentativas, encontra-se a representação literária como exercício de investigação de um dado objeto de estudo. Ora, se nenhum método investigativo ocupa a posição única como meio para se chegar à verdade, mas todos são relatos interpretativos de uma investigação, o estilo literário apresenta-se como uma representação estilizada em substituição ao discurso realista tradicional. As descrições etnográficas são, assim, expandidas e alteradas para incluir poesia, ficção, invenção autobiográfica, etc. O estilo literário é usado para indicar ao leitor que a exposição não funciona como um retrato da realidade, mas é uma ação interpretativa dirigida a uma comunidade de interlocutores.

Gergen e Gergen (2006) destacam que, para muitos pesquisadores qualitativos, esse tipo de narrativa é especialmente atraente, pois oferece um alcance expressivo cada vez maior e uma oportunidade de chegar a audiências de fora do contexto acadêmico. Podemos dizer, no entanto, que em tal contexto (lugar em que o discurso científico é enaltecido), o uso do estilo literário para se fazer pesquisa ganha resistência. Todavia, existem pesquisadores entusiasmados com alternativas ao discurso que se pretende objetivo para a prática de investigação qualitativa. Se o estilo literário é encarado como 
um estilo não sério, que ele traga menos seriedade e mais encantamento para a sisuda Academia.

\section{O fecho}

Nesse texto, fizemos uma reflexão a respeito de diferentes perspectivas acerca da linguagem e da ciência e como estas conjugam-se com a literatura, mais precisamente, com obras literárias e com o estilo literário. Podemos dizer que duas perspectivas configuram-se basilares para o pensamento ocidental no que concerne à relação da linguagem com as coisas no mundo. De um lado, teríamos o entendimento de que as palavras são entidades objetivas que ligam uma forma a um significado, tido como essencial e universal a todos os homens. De acordo com essa lógica, as línguas humanas seriam instrumentos de que dispomos para falarmos objetivamente sobre as coisas, configurando-se como um sistema de representações utilizado para descrevermos a realidade como um retrato fiel e verdadeiro. A linguagem também poderia apresentar outras vocações, como a persuasão e a criação do belo. Todavia, tais funções não estariam no núcleo da linguagem, mas sim em sua periferia. Em posição nuclear estaria a função imanente de representar entidades estáveis. Do outro lado, teríamos a língua não como um sistema de representação, mas como uma prática estabelecida em um dado contexto. A linguagem estaria no centro de uma ligação entre o indivíduo e a organização social. Sob essa ótica, as significações são construídas e não transcendentais.

O discurso científico, no pensamento ocidental, encontra bases nas perspectivas essencialistas, em que se pressupõe a possibilidade de uma linguagem neutra e objetiva para descrever o indivíduo e o meio em que vive. No contexto pós-moderno, essa 
concepção de linguagem vai ser questionada, desconstruindo certos pressupostos metodológicos nas ciências sociais.

A pergunta que fazemos é: devemos privilegiar um discurso no que concerne à investigação das práticas sociais? Ora, a linguagem não reflete a realidade social, mas produz significações que criam essa realidade. Há, portanto, várias criações dessa realidade e um meio para observá-las podemos encontrar em obras literárias. Sem dúvida, uns criam essa realidade com mais maestria do que outros, mas não podemos dizer que um relato é mais verdadeiro do que o outro.

No campo da investigação qualitativa, os pressupostos ontológicos consideram a realidade subjetiva e múltipla e, epistemologicamente, o pesquisador interage com os objetos e sujeitos da pesquisa. Nesse caso, o que o pesquisador julga importante em um grande número de observações possíveis, bem como a maneira como ele avalia cada observação em relação às outras, determina a construção obtida. Assim, podemos caracterizar os atos de observação e os relatórios de pesquisa como exercícios de interpretação. Em tais exercícios, a escrita científica tradicional, permeada por uma retórica da objetividade e da impessoalidade, pode dar lugar a escritas alternativas que valorizem a criatividade e a singularidade de cada pesquisador. A escrita acadêmica pode ser dotada de leveza e graça, numa estetização que se aproxime de produções literárias. Por exemplo, as descrições do pesquisador podem vir em forma de poemas, cartas, diários, crônicas, etc.

Com base nas ponderações elencadas nesse trabalho, não podemos dizer que o estilo literário é inferior ao estilo tradicional de escrita acadêmica, que presume ser verdadeiro, pois descreve o real de forma mais fidedigna. Ele é diferente, mas não inferior. Estilos alternativos à escrita tradicional, no campo da investigação qualitativa, 
não garantem melhores produtos, mas libertam os pesquisadores dos grilhões do rigor teórico que se pretende objetivo e confiável.

\section{Referências}

ARROJO, R. (Org.). O signo desconstruído: implicações para a tradução, a leitura e o ensino. 2 ed. Campinas, SP: Pontes, 2003.

BECKER, H. S. Falando da sociedade. Rio de Janeiro. Zahar, 2009.

CANDIDO, A. Literatura e sociedade. Rio de Janeiro: Ouro sobre Azul, 2006.

DENZIN, N. K.; LINCOLN, Y. S. (Orgs.). O planejamento da pesquisa qualitativa: teorias e abordagens. 2 ed. Porto Alegre: Artmed, 2006.

DURÃO, S. A. Reflexões sobre a metodologia de pesquisa nos estudos literários. D.E.L.T.A., 31-especial, p. 377-390, 2015.

GERGEN, M. M.; GERGEN, K. J. Investigação qualitativa-tensões e transformações. In: DENZIN, N. K.; LINCOLN, Y. S. et al. O planejamento da pesquisa qualitativa: teorias e abordagens. Porto Alegre: Artmed, 2006. p. 367-388.

MARTINS, H. Três caminhos na filosofia da linguagem. In: MUSSALIM, F.; BENTES, A. C. (Orgs.). Introdução à linguística: fundamentos epistemológicos. Vol. 3. São Paulo: Cortez, 2001, p. 439-473.

MARCONDES, D. Iniciação à história da filosofia: dos pré-socráticos a Wittgenstein. Rio de Janeiro, Jorge Zahar. 1997.

RICHARDSON, L. New writing practices in qualitative research. Sociology of Sports Journal, 17. p. 5-20, 2000.

Recebido em 20 de janeiro de 2018.

Aceito em 25 de março de 2018. 